\title{
Genomic Variability of Staphylococcus aureus and the Other Coagulase-Positive Staphylococcus Species Estimated by Macrorestriction Analysis Using Pulsed-Field Gel Electrophoresis
}

\author{
ROMAN PANTU゚ČEK, ${ }^{1}$ FRIEDRICH GÖTZ, ${ }^{2}$ JIŘÍ DOŠKAŘ, ${ }^{1}$ AND STANISLAV ROSYPAL ${ }^{1 *}$ \\ Department of Genetics and Molecular Biology, Faculty of Science, Masaryk University, 61137 Brno, Czech Republic, ${ }^{1}$ \\ and Lehrstuhl für Mikrobielle Genetik, Universität Tübingen, 72076 Tübingen 1, Germany ${ }^{2}$
}

\begin{abstract}
The genomic DNAs of 95 culture collection and hospital Staphylococcus aureus subsp. aureus strains of various origins, as well as the genomic DNAs of other coagulase-positive Staphylococcus species, were cleaved with restriction endonuclease $S m a I$ and subjected to pulsed-field gel electrophoresis. The levels of similarity of the $S m a I$ restriction patterns of the $S$. aureus subsp. aureus strains varied from 30 to $100 \%$, which is considered characteristic of this species; thus, these organisms belonged to the same species restriction group. Within this range of similarity values $13 \mathrm{~S}$. aureus intraspecies restriction groups were identified, and each group consisted of strains whose levels of similarity ranged from 65 to $100 \%$. S. aureus subsp. aureus $\mathrm{CCM} 885^{\mathrm{T}}(\mathrm{T}=$ type strain) belonged to the major intraspecies restriction group that comprised $39 \%$ of the $S$. aureus strains which we studied. The strains of the other coagulase-positive staphylococci, including Staphylococcus aureus subsp. anaerobius, Staphylococcus hyicus, Staphylococcus intermedius, Staphylococcus delphini, and Staphylococcus schleiferi subsp. coagulans, clustered with their type strains in separate restriction groups. $S$. aureus subsp. aureus exhibited almost no similarity to these species. We found 44-kb SmaI fragments in all of the $S$. aureus subsp. aureus and $S$. aureus subsp. anaerobius strains studied, and these fragments are considered characteristic of the species $S$. aureus. The high level of homology of these fragments was confirmed by the results of DNA hybridization experiments in which we used representatives of individual intraspecies restriction groups. Of the other staphylococci studied, only Staphylococcus epidermidis and one strain of $S$. hyicus contained these fragments. However, the levels of homology between these fragments and the fragments of $S$. aureus were found to be very low.
\end{abstract}

Classification of genomic DNA restriction patterns by pulsed-field gel electrophoresis (PFGE) has been shown to be a useful tool for investigating the source, transmission, and spread of nosocomial infections and particularly for epidemiologic typing and determining the genetic relatedness of methicillin-resistant Staphylococcus aureus strains $(3,7,8,10,12,15$, $17,27-30,34-36,40$ ), as well as for differentiating clumping factor-negative oxacillin-resistant strains from clumping factorpositive oxacillin-resistant strains (31). Hesselbarth et al. (13) and Khambaty et al. (19) used PFGE to determine the genome variability of Staphylococcus intermedius. The importance of PFGE as a tool for epidemiological analysis of the coagulasenegative organisms Staphylococcus epidermidis and/or Staphylococcus haemolyticus has been discussed by Linhardt et al. (22), Goering and Duensing (10), and Degener et al. (4). This method has also been shown to be useful for studying chromosomal polymorphism in different Staphylococcus species (9, $21,33)$.

In this study we focused on the following questions. (i) What was the variability in the restriction fragment patterns of genomic DNAs within Staphylococcus aureus subsp. aureus as determined by using PFGE and a large sample of strains that had different origins? We tried to express this variability by determining the number of intraspecies restriction groups (ISRGs). An ISRG is a group of strains that belong to the

* Corresponding author. Mailing address: Department of Genetics and Molecular Biology, Faculty of Science, Masaryk University, Kotlářská 2, 61137 Brno, Czech Republic. Phone: (0042-5)4112 9549. Fax: (0042-5)4121 1214. Electronic mail address: rosypal@sci.muni.cz. same species and have similar restriction patterns. (ii) What ISRGs were the predominant $S$. aureus subsp. aureus ISRGs? (iii) Were there certain restriction fragments that were specific for $S$. aureus subsp. aureus and were found in all strains of this subspecies? (iv) Could the coagulase-positive taxa S. aureus subsp. aureus, Staphylococcus aureus subsp. anaerobius (5), Staphylococcus hyicus (6), S. intermedius (11), Staphylococcus delphini (38), and Staphylococcus schleiferi subsp. coagulans (16) be distinguished on the basis of their restriction fragment patterns?

\section{MATERIALS AND METHODS}

Staphylococcus strains. The following strains were obtained from the Czech Collection of Microorganisms, Masaryk University, Brno, Czech Republic: $S$. aureus subsp. aureus CCM $885^{\mathrm{T}}$ ( $\mathrm{T}=$ type strain), CCM 1484, CCM 2287, CCM 2286, CCM 2323, CCM 2353, CCM 2512, CCM 5755, CCM 5756, CCM 5757. CCM 5972, CCM 5973, and CCM 6188; S. aureus subsp. anaerobius CCM $3823^{\mathrm{T}}$, CCM 3824, and CCM 3826; Staphylococcus auricularis CCM 3991 ${ }^{\mathrm{T}}$; Staphylococcus capitis CCM $2734^{\mathrm{T}}$; Staphylococcus caprae CCM $3573^{\mathrm{T}}$; Staphylococcus caseolyticus CCM $3540^{\mathrm{T}}$; Staphylococcus chromogenes CCM $3387^{\mathrm{T}}$; Staphylococcus cohnii CCM $2736^{\mathrm{T}}$; S. delphini CCM $4115^{\mathrm{T}}$ and CCM 4184; S. epidermidis CCM $2124^{\mathrm{T}}$ and CCM 50; Staphylococcus equorum CCM $3832^{\mathrm{T}}$; Staphylococcus felis CCM 4196' ; Staphylococcus gallinarum CCM 3572 ; S. haemolyticus CCM $2737^{\mathrm{T}}$; Staphylococcus hominis CCM 3474T ; S. hyicus CCM 2995, CCM 2994, and CCM 2368 ; Staphylococcus kloosii CCM $3834^{\mathrm{T}}$; S. intermedius CCM $5739^{\mathrm{T}}$, CCM 2885, and CCM 2618; Staphylococcus lentus CCM 3472 ${ }^{\mathrm{T}}$; Staphylococcus

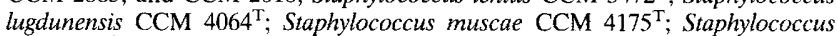
pasteuri CCM 4389 ${ }^{\mathrm{T}}$; Staphylococcus piscifermentans CCM $4345^{\mathrm{T}}$; Staphylococcus saprophyticus CCM $883^{\mathrm{T}}$; Staphylococcus schleiferi subsp. schleiferi CCM $4070^{\mathrm{T}}$; S. schleiferi subsp. coagulans CCM $4313^{\mathrm{T}}$ and CCM 4315; Staphylococcus sciuri CCM $3473^{\mathrm{T}}$; Staphylococcus simulans CCM $2705^{\mathrm{T}}$; Staphylococcus warneri CCM $2730^{\mathrm{T}}$; and Staphylococcus xylosus CCM $2738^{\mathrm{T}}$. Staphylococcus carnosus DSM $20501^{\mathrm{T}}$ was obtained from the German Collection of Microorganisms and Cell Cultures, Braunschweig, Germany. The $S$. aureus strains whose designations 
begin with PS (PS strains) were obtained from V. Hájek, Faculty of Medicine, Olomouc, Czech Republic. $S$ aureus NCTC $8325-4$ was obtained from P. A. Pattee, Iowa State University, Ames. S. aureus NCTC 8511 and S26 were obtained from R. Z. Korman (United States). S. epidermidis O-47, Tü 3298 (= DSM 3095), and RP62a were obtained from the laboratory of F. Götz. Clinical $S$. aureus whose designations begin with FN and $\mathrm{R}$ were obtained from seven hospitals in Brno, Czech Republic, over the 3-year period from 1991 to 1994. The biochemical characteristics of these strains (they produce coagulase, clumping factor hyaluronidase, and alkaline phosphatase, form acid aerobically from D-mannitol, sucrose, and D-trehalose, produce acetoin from glucose, and reduce nitrates) are characteristics which have been described previously for $S$. aureus (14).

Preparation of DNA for PFGE. DNA was isolated by the method described by Linhardt et al. (22) and Prevost et al. (27), with some modifications. Each $S$. aureus strain was grown in $20 \mathrm{ml}$ of $2 \times \mathrm{YT}$ medium at $37^{\circ} \mathrm{C}$ to an optical density at 600 of 0.2 to 0.3 . The bacteria were harvested, washed twice in $2 \mathrm{ml}$ of a buffer containing $10 \mathrm{mM}$ Tris- $\mathrm{HCl}, 10 \mathrm{mM}$ EDTA, $10 \mathrm{mM}$ EGTA [ethylene glycol bis( $\beta$-aminoethyl ether)- $N, N, N^{\prime}, N^{\prime}$-tetraacetic acid], and $1 \mathrm{M} \mathrm{NaCl}(\mathrm{pH} 7.5)$, and resuspended in $200 \mu$ l of the same buffer. The suspension was then immediately mixed with $200 \mu \mathrm{l}$ of $2 \%$ low-melting-point agarose (type VII; Sigma Chemical $\mathrm{Co}$.) in $50 \mathrm{mM}$ Tris-HCl-5 mM EDTA (pH 8.0$)$ and stored at $55^{\circ} \mathrm{C}$, and then 20 $\mu \mathrm{l}$ of a $0.5-\mathrm{mg} / \mathrm{ml}$ lysostaphin (Sigma Chemical Co.) stock solution was added. After agarose blocks were cast, they were transferred into $1 \mathrm{ml}$ of lysis buffer ( 6 $\mathrm{mM}$ Tris- $\mathrm{HCl}, 100 \mathrm{mM}$ EDTA, $1 \mathrm{M} \mathrm{NaCl}, 0.5 \%$ Brij $58,0.2 \%$ sodium deoxycholate, $0.5 \% \mathrm{~N}$-lauroylsarcosine; $\mathrm{pH} 7.6$ ) supplemented with $500 \mu \mathrm{g}$ of lysozyme (Sigma Chemical Co.) and $10 \mu \mathrm{g}$ of RNase and incubated for $3 \mathrm{~h}$ at $37^{\circ} \mathrm{C}$. The lysis buffer was then replaced with $1 \mathrm{ml}$ of proteolysis buffer (0.25 M EDTA, 20 mM EGTA, $1 \% N$-lauroylsarcosine; pH 9.0) containing $500 \mu \mathrm{g}$ of proteinase K (Sigma Chemical Co.). Digestion was performed for $12 \mathrm{~h}$ at $55^{\circ} \mathrm{C}$. The agarose blocks were washed five times with $25 \mathrm{ml}$ of TE buffer and stored at $4^{\circ} \mathrm{C}$ in TE buffer.

Restriction enzyme digestion and PFGE. SmaI (Boehringer Mannheim) and Sst II (Sigma Chemical Co.) were used for restriction enzyme cleavage. Cleavage was performed with $8 \mathrm{U}$ of enzyme (for agarose blocks that were 1 by 1 by $5 \mathrm{~mm}$ ) overnight. PFGE was performed by using a CHEF-DR II system (Bio-Rad Laboratories, Inc.) and $1.2 \%$ agarose gels at $14^{\circ} \mathrm{C}$ in $1 \times$ TAE buffer. A constant voltage of $170 \mathrm{~V}$ was applied with increasing pulse times of 1 to $65 \mathrm{~s}$ over a period of $36 \mathrm{~h}$. To precisely estimate fragment sizes, we used pulse times of 0.1 to 35 and 10 to $90 \mathrm{~s}$ for small and large fragments, respectively. Bacteriophage lambda DNA concatemers from $c$ I857S7 (Promega) and HindIII restriction fragments of bacteriophage lambda DNA were used as size markers. The gels were stained for $1 \mathrm{~h}$ in ethidium bromide, destained in water, and photographed under UV light $(302 \mathrm{~nm})$.

Hybridization experiments. The 44-kb SmaI fragment from $S$. aureus CCM $885^{\mathrm{T}}$ was isolated from a gel after we performed PFGE with low-melting-point agarose (Sigma Chemical Co.) and was labeled by a nonradioactive method (DIG DNA labeling and detection kit; Boehringer Mannheim). SmaI-digested DNAs of other strains resolved by PFGE were transferred to nylon membranes (Boehringer Mannheim) by Southern blotting. The membranes were prehybridized and hybridized with the probe at $68^{\circ} \mathrm{C}$, and the bands were detected as recommended by the supplier.

Estimating levels of restriction pattern similarity. The restriction patterns of DNAs isolated from different strains were compared quantitatively by using the formula proposed by Upholt (37) and Nei and $\mathrm{Li}(24), F_{x y}=2 n_{x y} /\left(n_{x}+n_{y}\right)$, where $F_{x y}$ is the proportion of restriction fragments that are found in both of the strains compared; $n_{x}$ and $n_{y}$ are the total numbers of restriction fragments found in strains $x$ and $y$, respectively; and $n_{x w}$ is the number of restriction fragments found in both strain $x$ and strain $y$. The gels were evaluated visually. Only patterns on the same gel were compared. $F_{x y}$ values were estimated by performing three independent experiments, and nonequimolar fragments (including partially digested fragments) were not considered when we estimated levels of restriction pattern similarity. Distance matrices of $F_{x y}$ values were subjected to a cluster analysis in order to estimate the levels of restriction pattern similarity for strains as described by Snopková et al. (33). The unweighted pair group average linkage method was used to construct dendrograms.

\section{RESULTS}

In order to estimate the proper levels of similarity of SmaI restriction patterns for forming ISRGs, we subjected $23 \mathrm{~S}$. aureus PS strains to PFGE and compared their restriction patterns. We chose these strains because (i) they had different origins; (ii) Pattee et al. (26) and Rosdahl et al. (28) found that strains sensitive to phages belonging to the same lytic group produced similar restriction patterns; and (iii) they are well known internationally because they are used as the standard hosts for the phages belonging to the International Standard Set for phage typing. On the basis of their sensitivity to the International Standard Set of phages for phage typing, the PS strains were divided into five phage lytic groups $(2,23)$. The
SmaI restriction patterns of these organisms are shown in Fig. 1A. The dendrogram in Fig. $2 \mathrm{~A}$ shows that most of the PS strains that were sensitive to the phages belonging to the same lytic group were members of the same cluster at levels of similarity ranging from 65 to $100 \%$. Clusters were formed by the strains that were sensitive to the phages belonging to lytic groups I, II, III, and V. Only strains PS $3 \mathrm{~A}$ and PS 42E (members of lytic groups II and III, respectively) were not placed in their appropriate clusters; the levels of similarity between these strains and the members of the clusters were less than $65 \%$ similarity. Strains PS 95 and PS 187, which belonged to miscellaneous lytic group $M$, formed separate clusters, and PS 81 strain, a member of the same lytic group, clustered with the strains belonging to lytic group I, which is consistent with the results of Asheshow and Winkler (1), who reported that this organism was related to group I.

Our results indicated that the PS strains belonging to the same lytic group were genetically closely related since the levels of similarity of their restriction patterns ranged from 65 to $100 \%$. However, this does not mean that these organisms are related only on the basis of sensitivity to certain bacteriophages. It does mean that their genomes are similar (related) since $S m a$ I restriction sites are distributed along the whole $S$. aureus chromosome, as shown by the restriction map constructed by Pattee (25). Since other authors (see below) also obtained levels of relatedness ranging from 65 to $100 \%$ for the strains which they studied, we used this range to estimate the boundaries of the ISRGs. Using these boundaries, we identified 13 ISRGs among $95 \mathrm{~S}$. aureus strains that had different origins. The characteristics of these ISRGs are shown in Table 1. The 95 strains studied produced 78 different SmaI restriction patterns.

In order to make it possible to place unknown strains into their appropriate ISRGs (see below), one strain of each group was chosen as its representative. The SmaI restriction patterns of these representative strains are shown in Fig. 1B. The dendrogram in Fig. 2B shows that the interstrain levels of similarity were less than $65 \%$ but not less than $30 \%$ when these strains were examined.

The ISRGs differed from one another in the numbers of strains that they included (Table 1). ISRG 1 was the largest ISRG and contained $39 \%$ of all of the $S$. aureus strains studied. This group included well-defined culture collection strains, as well as PS strains sensitive to the phages belonging to lytic group III. The PS strains which were hosts for the phages belonging to lytic group I were members of ISRG 6 , which contained $14 \%$ of the strains studied. Each of the other ISRGs contained less than $10 \%$ of the 95 strains studied.

As shown in Fig. 3, some restriction fragments seemed to characterize restriction groups being shared by all of the strains of an ISRG. In addition, some fragments occurred in several ISRGs; for example, a 134-kb fragment was found in members of ISRGs 2, 5, and 7 through 9, a 116-kb fragment was found in members of ISRGs 1 and 3 through 10 , a 76-kb fragment was found in members of ISRGs 4, 5, and 8 through 11 , a 23-kb fragment was found in members of ISRGs 1 through 6,8 , and 9, a 19-kb fragment was found in members of ISRGs 1 through 5,9 , and 10 , and a $9.8-\mathrm{kb}$ fragment was found in members of ISRGs 1 through 9.

SmaI restriction fragments that were $44 \pm 1.5 \mathrm{~kb}$ long were found in all of the $S$. aureus strains which we studied.

We also studied whether the restriction patterns of the $S$. aureus subsp. aureus strains were similar to the restriction patterns of the other coagulase-positive Staphylococcus species. In such a study clustering the strains of different species requires the use of the type strains of the species studied; the 
A
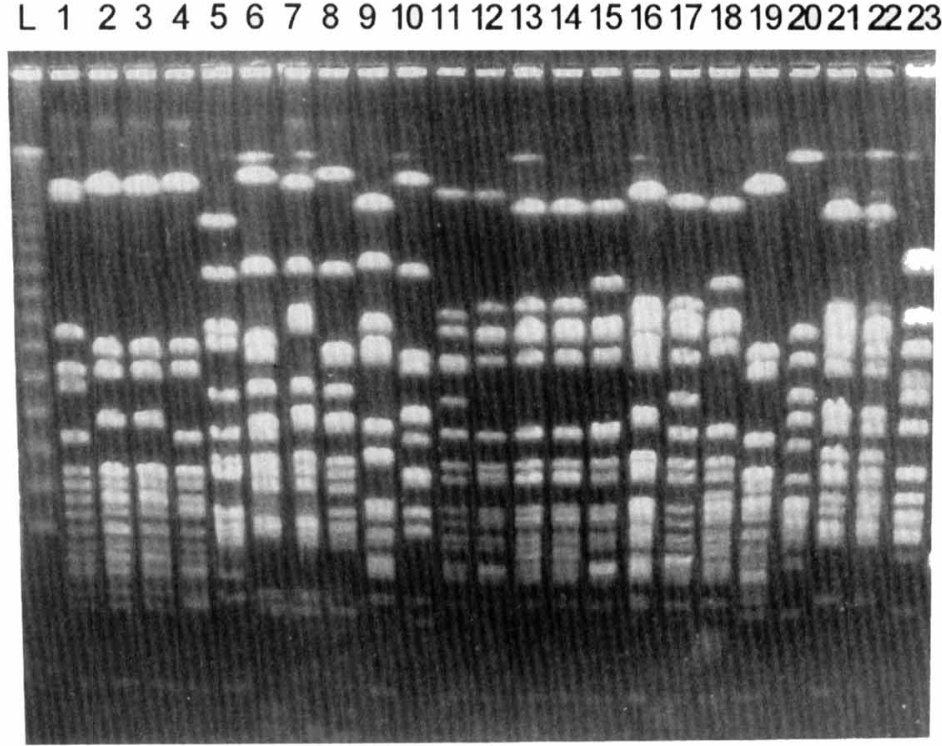

B

$1234567891011121314 \mathrm{~L}$

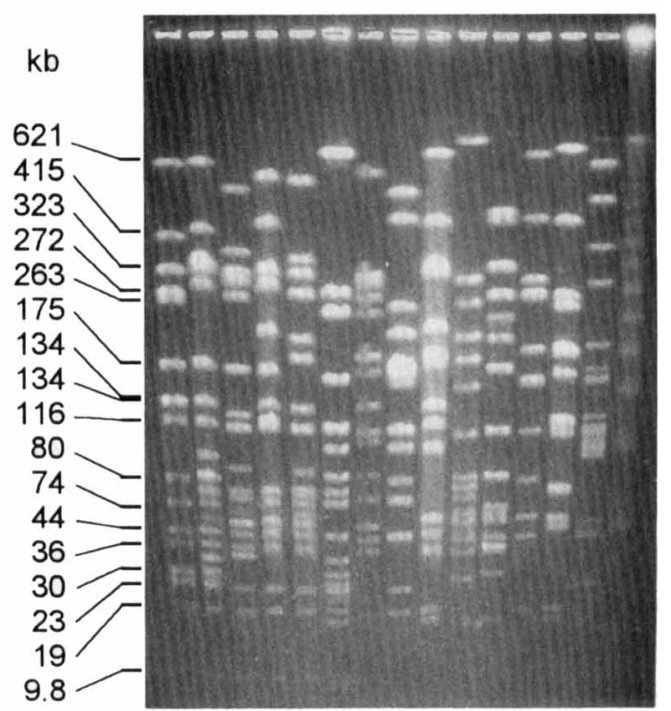

FIG. 1. (A) PFGE of SmaI-cleaved genomic DNAs of $S$. aureus strains used as hosts for the phages belonging to the International Standard Set. Lane L, molecular ize marker (lambda concatemers). Lane 1, PS 29; lane 2, PS 52; lane 3, PS 52A; lane 4, PS 80; lane 5 , PS 3 A; lane 6 , PS 3C; lane 7 , PS 55; lane 8 , PS 71; lane 9, PS 6; lane 10, PS 42E; lane 11, PS 47; lane 12, PS 53; lane 13, PS 75; lane 14, PS 54; lane 15, PS 77; lane 16, PS 83A; lane 17, PS 84; lane 18, PS 85; lane 19, PS 81; lane 20, PS 95; lane 21, PS 94; Iane 22, PS 96; lane 23, PS 187. (B) PFGE of SimaI-cleaved genomic DNAs of representative strains of the S. aureus ISRGs listed in Table 1. Lane 1, CCM 885 ; lane 2, PS 85; lane 3, FN 15; lane 4, PS 3A; lane 5, CCM 2323; lane 6, PS 80; lane 7, PS 96; lane 8, CCM 2287; lane 9, PS 55; lane 10, PS 95; lane 11, PS 187; lane 12, FN 4; lane 13, PS 42E; lane 14, S aureus subsp. anaerobius CCM $3823^{\mathrm{T}}$; lane L, molecular size marker (lambda concatemers). The estimated sizes of $S$. aureus CCM $885^{\mathrm{T}}$ SmaI fragments are indicated on the left.

strains belonging to the same species should cluster with the type strain, forming a species restriction group. The range of levels of similarity of the restriction fragment patterns of members of a species restriction group depends on the genomic variability of the strains belonging to the species (33). This study was performed by using two restriction endonucleases, SmaI (Fig. 4) and SstII (data not shown). As Fig. 5 shows, the

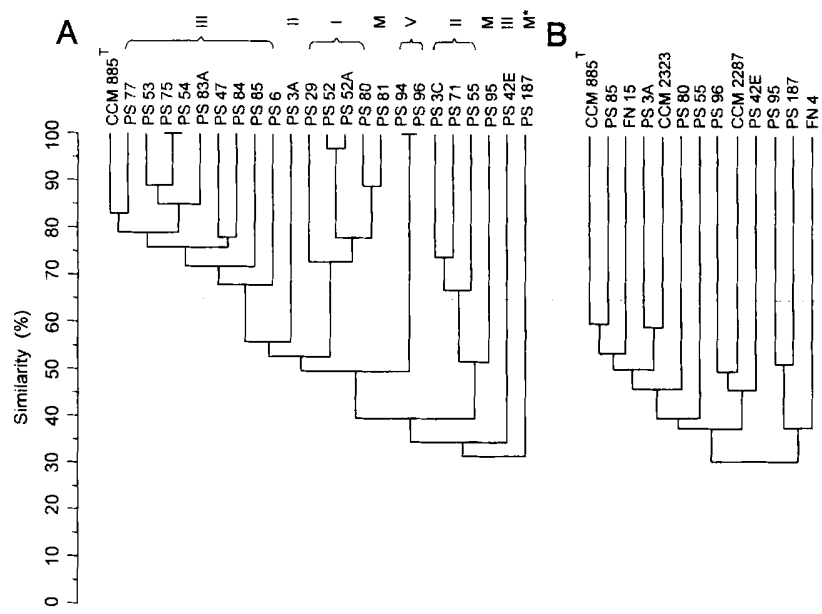

FIG. 2. (A) Dendrogram showing the levels of similarity of the SmaI restriction patterns of the genomic DNAs of $S$. aureus strains used as hosts for the phages belonging to the International Standard Set for phage typing. The phage lytic groups to which the PS strains belong are indicated at the top. $S$. aureus CCM $885^{\mathrm{T}}$ was included for comparison. (B) Dendrogram showing the levels of similarity of the SmaI restriction patterns of the genomic DNAs of $S$. aureus strains that were used as representatives of ISRGs. Strain PS 187 has not belonged to the International Standard Set for phage typing since 1974 (2). dendrograms showing the levels of similarity of the SmaI and SstII restriction patterns of the genomic DNAs of the coagulase-positive Staphylococcus strains are very similar. Individual coagulase-positive strains clustered together with their appropriate type strains in separate species restriction groups. The same clusters were obtained with both $S m a I$ and $S s t I I$ restriction endonucleases. The range of levels of similarity was 21 to $100 \%$ when SmaI was used, and the range of levels of similarity was 30 to $100 \%$ when SstII was used. The coagulase-negative organism $S$. schleiferi subsp. schleiferi CCM $4070^{\mathrm{T}}$ clustered with the coagulase-positive strains of $S$. schleiferi subsp. coagulans. Both of the dendrograms also showed that the levels of similarity between the two subspecies of $S$. aureus and the other coagulase-positive species were very low (about 3\%). The level of similarity between $S$. aureus subsp. anaerobius and the type strain $S$. aureus subsp. aureus CCM $885^{\mathrm{T}}$ was only $17 \%$.

We estimated the sizes of the restriction fragments of $S$. aureus CCM $885^{\mathrm{T}}$. Figure 1 shows that the restriction fragment sizes ranged from 9.8 to $621 \mathrm{~kb}$. The sizes of $13 \mathrm{SmaI}$ fragments corresponded to the sizes of fragments C, D, G, H, I, J, K, L, and $\mathrm{M}$ and four small fragments whose sizes in $S$. aureus NCTC 8325 had been estimated previously by Pattee (25) and Pattee et al. (26). The sizes of the restriction fragments in whole samples of the strains which we studied ranged from 7.5 to approximately $1,200 \mathrm{~kb}$. The molecular size of the genome of $S$. aureus CCM $885^{\mathrm{T}}$ was estimated to be $2,766 \pm 45 \mathrm{~kb}$. The average molecular sizes of the genomes of $95 \mathrm{~S}$. aureus subsp. aureus strains ranged from 2,707 to $3,073 \mathrm{~kb}$. The genome sizes of coagulase-positive species differed from one another (Table 2).

As stated above, a 44-kb $S m a I$ fragment was found in all of the $S$. aureus strains which we studied. This fragment corresponds to fragment $\mathrm{L}$ on the genome map of $S$. aureus NCTC 
TABLE 1. Characterization of $S$. aureus subsp. aureus ISRGs

\begin{tabular}{|c|c|c|c|c|c|}
\hline Group & $\begin{array}{l}\text { Representative } \\
\text { strain }\end{array}$ & $\begin{array}{l}\text { No. of } \\
\text { strains }\end{array}$ & Designations of strains as received & $\begin{array}{l}\text { No. of SmaI } \\
\text { restriction } \\
\text { fragments }\end{array}$ & Range of $F_{x y}$ values \\
\hline ISRG 1 & $\mathrm{CCM} 885^{\mathrm{T}}$ & 37 & 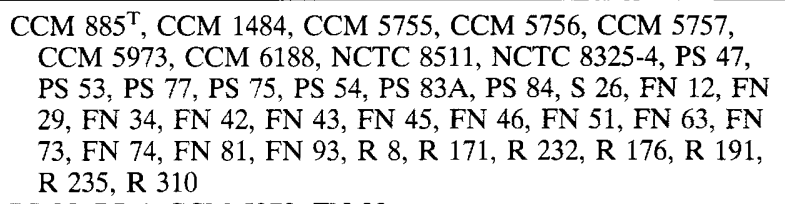 & $17-20$ & $0.68-1.00$ \\
\hline ISRG 2 & PS 85 & 4 & PS 85, PS 6, CCM 5972, FN 22 & $18-21$ & $0.65-0.75$ \\
\hline ISRG 3 & FN 15 & 6 & FN 15, FN 8, FN 25, R 120, R 152, R 206 & 18 & $0.75-1.00$ \\
\hline ISRG 4 & PS $3 \mathrm{~A}$ & 9 & PS 3 A, FN 36, R 26, R 30, R 117, R 119, R 138, R 665, R 787 & $18-20$ & $0.70-0.98$ \\
\hline ISRG 5 & CCM 2323 & 1 & CCM 2323 & 19 & 1.00 \\
\hline ISRG 6 & PS 80 & 13 & $\begin{array}{l}\text { PS } 80, \text { PS } 81, \text { PS } 29, \text { PS } 52 \text {, PS } 52 \text { A, SA } 812, \text { FN } 67 \text {, FN } 76, \text { R } \\
\quad 36, \text { R } 58, \text { R } 146 \text {, R } 153 \text {, R } 198\end{array}$ & $17-21$ & $0.70-0.98$ \\
\hline ISRG 7 & PS 55 & 5 & PS 55, PS 3C, PS 71, CCM 2353, R5 & $16-17$ & $0.65-0.74$ \\
\hline ISRG 8 & PS 96 & 5 & PS 96, PS 94, R 98, R 124, R 309 & 19 & $0.76-1.00$ \\
\hline ISRG 9 & CCM 2287 & 2 & CCM 2287, CCM 2286 & $17-18$ & 0.90 \\
\hline ISRG 10 & PS 42E & 2 & PS 42E, R 194 & $14-16$ & 0.73 \\
\hline ISRG 11 & PS 95 & 5 & PS 95, CCM 2512, R 84, R 44, R 104 & $16-20$ & $0.70-1.00$ \\
\hline ISRG 12 & PS 187 & 2 & PS $187, \mathrm{R} 826$ & 18 & 0.87 \\
\hline ISRG 13 & FN 4 & 4 & FN 4, FN 21, R 49, R 240 & 13 & $0.77-1.00$ \\
\hline
\end{tabular}

8325 (25). In addition, we determined whether this fragment also occurred in the type strains of 25 coagulase-negative Staphylococcus species. We found it only in S. epidermidis CCM $2124^{\mathrm{T}}$. Because of this, other $S$. epidermidis strains (strains CCM 50, O-47, Tü 3298, and RP62a) were also studied and were found to possess this fragment. Only one coagulasepositive non-S. aureus strain, S. hyicus CCM 2995, was found to have this fragment.

We also tried to determine whether the 44-kb fragments of the different strains were homologous. To do this, the $44-\mathrm{kb}$ fragment was isolated from $S$. aureus CCM $885^{\mathrm{T}}$ and used as a probe for hybridization in Southern blots of the restriction patterns of representative strains. Figure 6 shows that the $44-\mathrm{kb}$ fragments of all of the strains representing $S$. aureus subsp. aureus and $S$. aureus subsp. anaerobius ISRGs were homologous. The levels of homology with the 44-kb fragments of all of the $S$. epidermidis strains studied and $S$. hyicus CCM 2995 were low.

\section{DISCUSSION}

The 13 ISRGs described in this paper indicate that there is considerable genomic variability in $S$. aureus. Whether the ISRGs identified by using the strains which we studied represent all of the $S$. aureus subsp. aureus ISRGs or whether more ISRGs could still be found is not known. The range of similarity values $(65$ to $100 \%)$ used to define the boundaries of ISRGs based on SmaI restriction patterns was substantiated not only by the results described in this paper but also by the results described by other authors. The clusters of PS strains

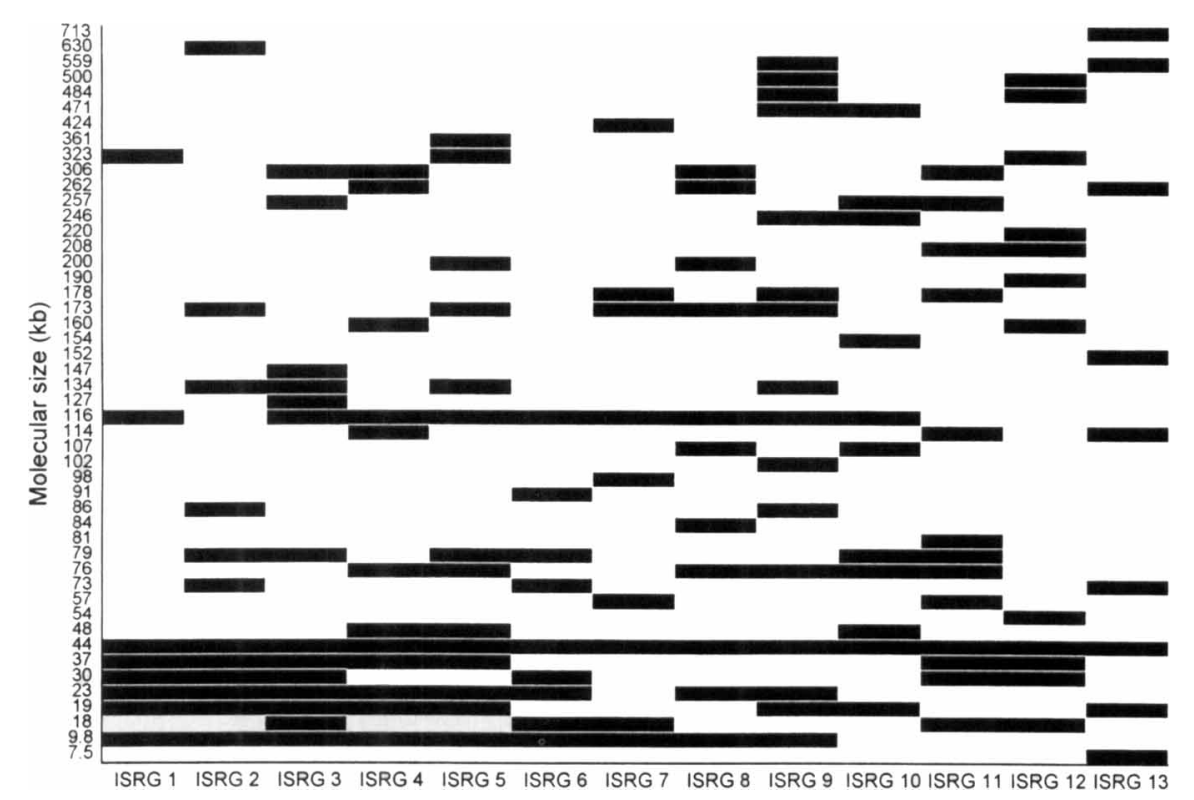

FIG. 3. Diagram showing the $S m a I$ restriction fragments found in all strains of $S$. aureus ISRGs 1 to 13 . The sizes of individual fragments are indicated on the left. 


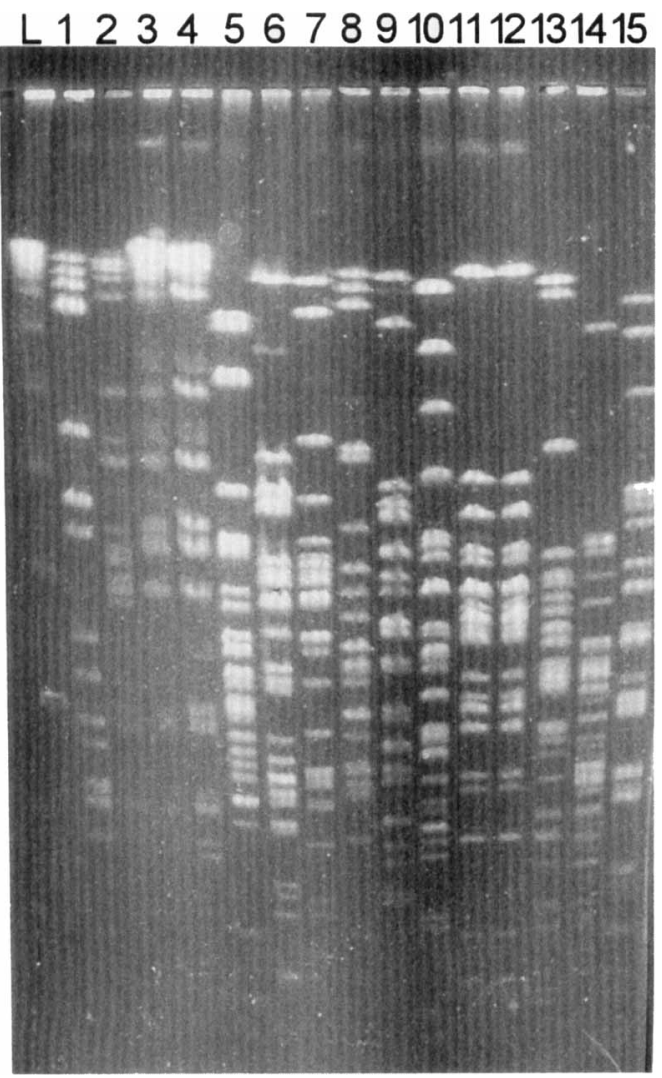

FIG. 4. PFGE of SmaI-cleaved genomic DNAs of coagulase-positive species. Lane 1, CCM $885^{\mathrm{T}}$; lane 2, CCM $3823^{\mathrm{T}}$; lane 3, CCM 3824; lane 4, CCM 3826; lane 5, CCM 2368 ${ }^{\mathrm{r}}$; lane 6, CCM 2994; lane 7, CCM 2995; lane 8, CCM 2618 lane 9, CCM 2885; lane $10, \mathrm{CCM} 5739^{\mathrm{T}}$; lane $11, \mathrm{CCM} 4115^{\mathrm{T}}$; lane $12, \mathrm{CCM}$ 4184; lane 13, CCM 4313 ${ }^{\mathrm{T}}$; lane 14, CCM 4315; lane 15, CCM 4070 ; lane L, molecular size marker (lambda concatemers).

obtained by using this range of similarity values are almost completely consistent with the clusters described by Rosdahl et al. (28). Only the position of strain PS $3 \mathrm{~A}$ is questionable; this strain was placed in different clusters in the two studies.

Struelens et al. $(35,36)$ used coefficients of similarity calculated by using SstII and/or SmaI macrorestriction PFGE patterns to analyze the DNA relatedness of methicillin-resistant $S$. aureus strains from different sources. These authors defined major macrorestriction genotypes (or clones) on the basis of common electrophoretic restriction patterns that differed by three or fewer fragments and exhibited similarity coefficients greater than $85 \%$, a value which is consistent with the range of similarity values estimated for our ISRGs.

Thus, the placement of closely related strains by Rosdahl et al. $(28)$ and Struelens et al. $(35,36)$ by using similarity values greater than $65 \%$ supports the range which we suggest for formation of ISRGs. We were not able to compare our data with the data which were used by El-Adhami et al. (8) and Stewart et al. (34) to construct dendrograms because the dendrograms of these authors were based on $p$ values, which expressed the estimated fractions of nucleotide differences in pairs of DNA samples.

We emphasize that our cluster analysis (Table 1) was performed with intention of forming as many ISRGs as possible in order to determine the variability of $S$. aureus subsp. aureus genomes. For this reason a large number of strains of different origins were included in this analysis. The results of our anal-
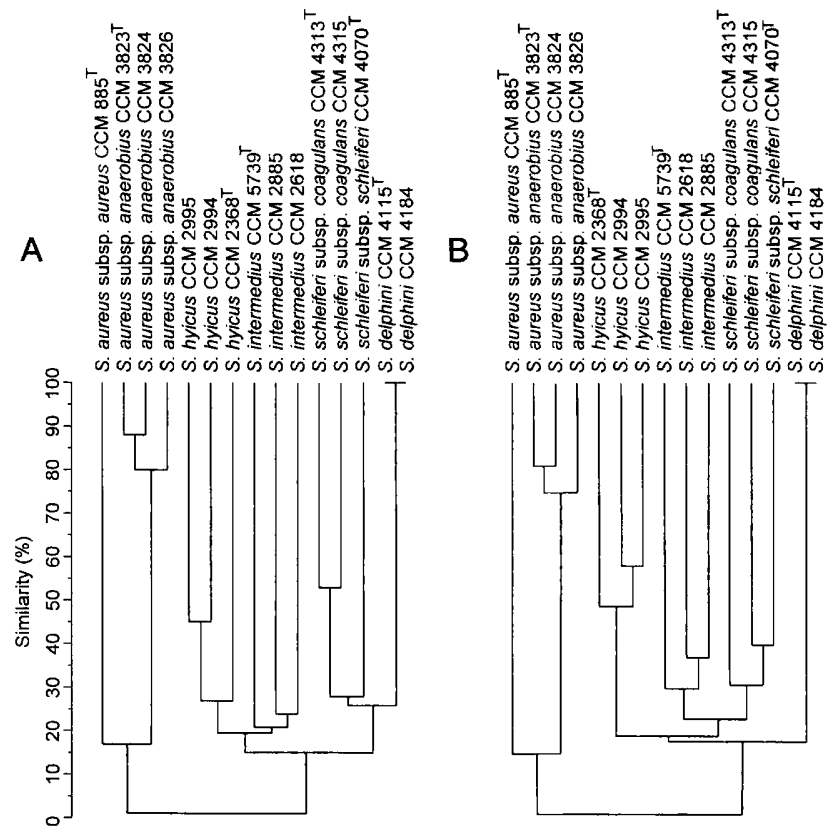

B

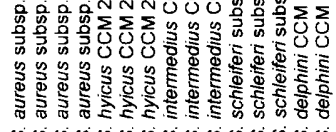

काष

FIG. 5. Dendrograms showing the levels of similarity of the SmaI (A) and SstII (B) restriction patterns of the genomic DNAs of different coagulase-positive species. The coagulase-negative organism $S$. schleiferi subsp. schleiferi CCM $4070^{T}$ was included for comparison.

ysis are fully reproducible if samples of the same size and composition are used. If the size and composition of the samples are changed, some differences at the threshold ISRG similarity values may occur. This follows from the data shown in Table 1 and Fig. 2A. On Fig. 2A S. aureus CCM $885^{\mathrm{T}}$ and PS 85 occur in the same cluster (range of levels of similarity, 65 to $100 \%$ ), whereas these strains were members of different ISRGs (ISRG 1 and ISRG 2) (Table 1). This was because the level of similarity of these strains was on the threshold $\left(F_{x y}=\right.$ $0.67)$. On the other hand, despite the great difference in the sizes of the samples used in the cluster analyses whose results are shown in Table 1 and Fig. 2A, the compositions of the other clusters correspond to the compositions of the ISRGs shown in Table 1.

The levels of similarity between strains that were representatives of different ISRGs (Table 1) were less than $65 \%$. This is shown in Fig. 2B, in which the highest level of similarity is $60 \%$ (the level of similarity between strains CCM $885^{\mathrm{T}}$ and PS 85 ) and the lowest level of similarity is $30 \%$ (the level of similarity between strain PS $42 \mathrm{E}$ and the other strains). Therefore, the representative strains can be used as reference (standard) strains to place unknown strains into the 13 ISRGs. To do this, the $F_{x y}$ value for the unknown strain and each of the representative strains of the ISRGs has to be determined. The unknown strain is placed into the ISRG, with whose representative strain exhibits the highest $F_{x y}$ value. This $F_{x y}$ value must be more than $65 \%$.

Shifts in restriction patterns may be due to mutations in restriction sites, as well as to the presence of prophages and other heterologous insertions of DNA in the chromosome of $S$. aureus (26). According to Smeltzer et al. (32), all of the SmaIdefined restriction fragment length polymorphisms observed in S. aureus NCTC 8325, NCTC 8325-4, KSI1201, KSI1202, S6C, and PS 42D were the direct result of the presence or absence of prophage DNA in the staphylococcal genome. Lina et al. (20) found that chromosomal integration of phage $118 I I$ could 
TABLE 2. Basic characterization of the coagulase-positive Staphylococcus species which we studied

\begin{tabular}{|c|c|c|c|c|c|}
\hline \multirow[b]{2}{*}{$\begin{array}{c}\text { Coagulase-positive species or } \\
\text { subspecies }\end{array}$} & \multirow[b]{2}{*}{ Strain $^{a}$} & \multicolumn{2}{|c|}{ Smal digestion } & \multicolumn{2}{|c|}{ Sst II digestion } \\
\hline & & $\begin{array}{l}\text { No. of } \\
\text { restriction } \\
\text { fragments }\end{array}$ & $\begin{array}{l}\text { Molecular size of } \\
\text { genome }(\mathrm{kb})^{h}\end{array}$ & $\begin{array}{l}\text { No. of } \\
\text { restriction } \\
\text { fragments }\end{array}$ & $\begin{array}{l}\text { Molecular size of } \\
\text { genome }(\mathrm{kb})\end{array}$ \\
\hline S. aureus subsp. aureus & CCM $885^{\mathrm{T}}$ & 17 & $2,766 \pm 45$ & $\mathrm{ND}^{c}$ & ND \\
\hline \multirow[t]{3}{*}{ S. aureus subsp. anaerobius } & CCM $3823^{\mathrm{T}}$ & 17 & $3,160 \pm 85$ & 16 & $3,010 \pm 129$ \\
\hline & CCM 3824 & 17 & $3,177 \pm 95$ & 16 & $3,061 \pm 137$ \\
\hline & CCM 3826 & 18 & $3,202 \pm 65$ & 16 & $3,073 \pm 98$ \\
\hline \multirow[t]{3}{*}{ S. hyicus } & CCM 2995 & 25 & $2,106 \pm 109$ & 30 & $2,170 \pm 75$ \\
\hline & CCM 2994 & 28 & $2,026 \pm 83$ & 32 & $2,104 \pm 105$ \\
\hline & CCM $2368^{\mathrm{T}}$ & 28 & $2,155 \pm 90$ & 35 & $2,249 \pm 81$ \\
\hline \multirow[t]{3}{*}{ S. intermedius } & CCM $5739^{\mathrm{T}}$ & 31 & $2,428 \pm 84$ & 35 & $2,478 \pm 75$ \\
\hline & CCM 2885 & 27 & $2,155 \pm 106$ & 37 & $2,086 \pm 92$ \\
\hline & CCM 2618 & 23 & $2,393 \pm 114$ & 34 & $2,481 \pm 119$ \\
\hline \multirow[t]{2}{*}{ S. schleiferi subsp. coagulans } & $\mathrm{CCM} 4313^{\mathrm{T}}$ & 33 & $1,812 \pm 78$ & 32 & $2,049 \pm 85$ \\
\hline & CCM 4315 & 27 & $1,583 \pm 75$ & 28 & $1,708 \pm 79$ \\
\hline S. delphini & $\mathrm{CCM} 4115^{\mathrm{T}}$ & 25 & $2,432 \pm 94$ & 37 & $2,537 \pm 112$ \\
\hline
\end{tabular}

\footnotetext{
${ }^{a}$ Designations as received.

${ }^{b}$ The molecular size of the strain CCM $885^{\mathrm{T}}$ genome was determined from measurements obtained from 10 gels; the molecular sizes of the genomes of the other strains were determined from measurements obtained from 3 gels.

cND, not done.
}

be responsible for minor stable variations in DNA restriction patterns in coagulase-negative staphylococci.

Do the ISRGs described in this paper apply only to the strains which we studied, or do they have general validity for the species $S$. aureus? The following facts support the latter possibility: (i) the set of strains which we studied included both hospital and culture collection strains having different origins; (ii) the PS strains used as hosts for the phages belonging to the International Standard Set, as well as the culture collection strains, were represented in all of the ISRGs; and (iii) strain CCM $885^{\mathrm{T}}$, as well as strains NCTC $8325-4$, NCTC 8325 , and NCTC 8511, which were used in genetic studies, were members of ISRG 1, which was the largest ISRG.

When we examined the results of our restriction fragment analysis of coagulase-positive strains, we concluded that the classification of these organisms into species restriction groups on the basis of the results of a cluster analysis of the levels of

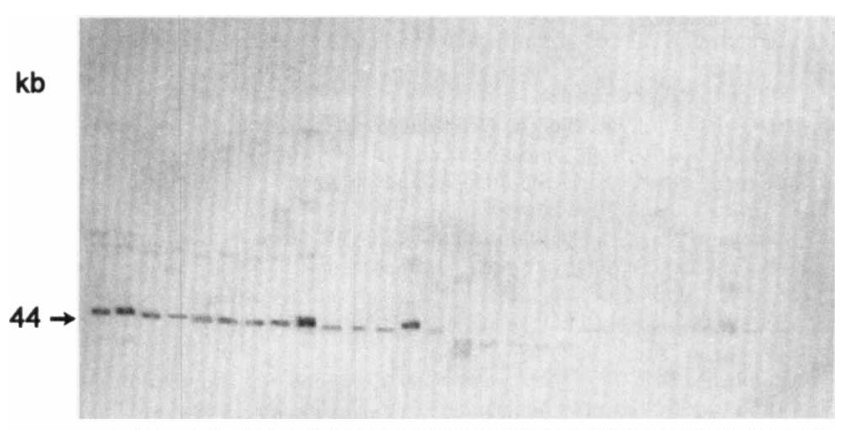

12345678910111213141516171819202122232425262728

FIG. 6. DNAs digested with SmaI were subjected to PFGE, transferred to a nylon membrane, and hybridized with the $S m a$ I 44-kb probe. Lanes 1 through 13 , $S$. aureus subsp aureus CCM $885^{\mathrm{T}}$, PS 85 , FN 15 , PS $3 \mathrm{~A}$, CCM 2323 , PS 80 , PS 96, CCM 2287, PS 55, PS 95, PS 187, FN 4, and PS 42E, respectively; lane 14, $S$. aureus subsp. anaerobius CCM $3823^{\mathrm{T}}$; lanes 15 and 16, S. hyicus CCM $2368^{\mathrm{T}}$ and CCM 2995, respectively; lane $17, S$. intermedius $C C M 5739^{\mathrm{T}}$; lane $18, S$. delphini CCM $4115^{\mathrm{T}}$; lane $19, S$ schleiferi subsp. coagulans CCM $4313^{\mathrm{T}}$; lanes 20 through 24, S. epidermidis CCM $2124^{\mathrm{T}}$, CCM 50, O-47, Tü 3298, and RP62, respectively; lane $25, S$. hominis $C C M 3474^{\mathrm{T}}$; lane $26, S$. wameri CCM $2730^{\mathrm{T}}$; lane $27, S$. pasteuri CCM $4390^{\mathrm{T}}$; lane $28, S$. xylosus CCM $2738^{\mathrm{T}}$ similarity of the restriction fragment patterns corresponded to their classification into separate species $(5,6,11,16,38)$. Strains of the coagulase-positive organism $S$. schleiferi subsp. coagulans clustered with the coagulase-negative organism $S$. schleiferi subsp. schleiferi CCM $4070^{\mathrm{T}}$, which is also consistent with the DNA-DNA relatedness results described by Igimi et al. (16).

The 44-kb SmaI fragments probably characterize the species $S$. aureus. Therefore, we suggest that in combination with other characteristics (production of coagulase, acetoin, and hyaluronidase and mannitol fermentation) the presence of a 44-kb fragment in the restriction fragment patterns of Staphylococcus strains could be used to identify organisms as $S$. aureus strains, as well as to differentiate this species from other Staphylococcus species. This suggestion is not weakened by the occurrence of a 44-kb fragment in $S$. epidermidis and $S$. hyicus strains. The 44-kb fragments of the latter species exhibit only low levels of homology with the 44-kb fragments of $S$. aureus strains (and the $S$. aureus CCM $885^{\mathrm{T}}$ probe). The same is true of $S$. caseolyticus CCM $3540^{\mathrm{T}}$, S. hominis CCM $3474^{\mathrm{T}}$, S. warneri CCM $2730^{\mathrm{T}}$, S. pasteuri CCM $4390^{\mathrm{T}}$, and S. xylosus CCM $2738^{\mathrm{T}}$, in which we found 42-kb fragments (Fig. 6) that exhibited only low levels of homology with the 44-kb fragment.

Carles-Nurit et al. (3) detected 44-kb SmaI fragments in both methicillin-resistant and methicillin-sensitive $S$. aureus strains and found that these fragments were identical. As stated above, the 44-kb fragment corresponds to $S m a I$ fragment L. In S. aureus NCTC 8325 one of the gene markers $(\Omega 1119$, a silent insertion of tetracycline resistance transposon Tn916) has been localized in this fragment $(18,25)$. Transposon Tn916 also occurs in SmaI fragments A, D, E, H, I, and M (25) on the physical and genetic map of $S$. aureus NCTC 8325. Wada et al. (39) localized six rRNA operons on the chromosome of $S$. aureus BB225, a derivative of strain NCTC 8325 . Two of these operons were located at the junctions of SmaI fragment $\mathrm{L}$ and neighboring fragments, and the others were located at the junctions of fragments $\mathrm{H}, \mathrm{I}, \mathrm{F}$, and $\mathrm{K}$ and fragment D. In $S$. aureus CCM $885^{\mathrm{T}}$ our $44-\mathrm{kb}$ fragment probe hybridized weakly with fragments, whose sizes corresponded to the sizes of labelled fragments A and D or fragments $E, H$, and I and to a 23-kb fragment on which the genes coding for rRNA 
and $\operatorname{Tn} 916$ were present. As the $44-\mathrm{kb}$ fragment probe hybridized strongly with the 44-kb fragments of different $S$. aureus strains and only weakly with fragments $\mathrm{A}$ and $\mathrm{D}$ or fragments $\mathrm{E}, \mathrm{H}$, and I and the 23-kb fragment, we assumed that there is another sequence on this fragment, which is conservative since it occurs in all of the ISRGs.

The average molecular size of the genomic DNA of $S$. aureus was estimated to be $2,878 \pm 20 \mathrm{~kb}$, which is consistent with the results obtained by Prevost et al. (27). However, in contrast to these authors, we did not find a genome molecular size less than $2,700 \mathrm{~kb}$ in the strains which we studied.

\section{ACKNOWLEDGMENTS}

This work was supported by grant Z/201-4 from the Czech Ministry of Health and by grant ERB 3510PL 928514 from the European Community.

\section{REFERENCES}

1. Asheshov, E. H., and K. C. Winkler. 1966. Staphylococcus aureus strains in the '52, 52A, 80, 81 complex.' Nature (London) 209:638-639.

2. Brandis, H., and W. Lenz. 1984. Staphylokokken-Bakteriophagen, p. 186214. In W. Meyer (ed.), Staphylokokken und Staphylokokken-Erkrankungen. VEB Gustav Fischer Verlag, Jena, Germany.

3. Carles-Nurit, M. J., B. Christophle, S. Broche, A. Gouby, N. Bouziges, and M. Ramuz. 1992. DNA polymorphism in methicillin-susceptible and methicillin-resistant strains of Staphylococcus aureus. J. Clin. Microbiol. 30:20922096.

4. Degener, J. E., M. E. O. C. Heck, W. J. Vanleeuwen, C. Heemskerk, A Crielaard, P. Joosten, and P. Caesar. 1994. Nosocomial infection by Staphylococcus haemolyticus and typing methods for epidemiological study. J. Clin. Microbiol. 32:2260-2265.

5. de la Fuente, R., G. Suarez, and K. H. Schleifer. 1985. Staphylococcus aureus subsp. anaerobius subsp. nov., the causal agent of abscess disease of sheep. Int. J. Syst. Bacteriol. 35:99-102.

6. Devriese, L. A., V. Hájek, P. Oeding, S. A. Meyer, and K. H. Schleifer. 1978 Staphylococcus hyicus (Sompolinsky 1953) comb. nov. and Staphylococcus hyicus subsp. chromogenes subsp. nov. Int. J. Syst. Bacteriol. 28:482-490.

7. Dominguez, M. A., H. Delencastre, J. Linares, and A. Tomasz. 1994. Spread and maintenance of a dominant methicillin-resistant Staphylococcus aureus (MRSA) clone during an outbreak of MRSA disease in a Spanish hospital J. Clin. Microbiol. 32:2081-2087.

8. El-Adhami, W., L. Roberts, A. Vickery, B. Inglis, A. Gibbs, and P. R. Stewart 1991. Epidemiological analysis of a methicillin-resistant Staphylococcus aureus outbreak using restriction fragment length polymorphism of genomic DNA. J. Gen. Microbiol. 137:2713-2720.

9. George, C. G., and W. E. Kloos. 1994. Comparison of the SmaI-digested chromosomes of Staphylococcus epidermidis and the closely related species Staphylococcus capitis and Staphylococcus caprae. Int. J. Syst. Bacteriol. 44: 404-409.

10. Goering, R. V., and T. D. Duensing. 1990. Rapid field inversion gel electrophoresis in combination with an rRNA gene probe in the epidemiological evaluation of staphylococci. J. Clin. Microbiol. 28:426-429.

11. Hájek, V. 1976. Staphylococcus intermedius, a new species isolated from animals. Int. J. Syst. Bacteriol. 26:401-408.

12. Hall, L. M., J. Z. Jordens, and F. Wang. 1989. Methicillin-resistant Staphy lococcus aureus from China characterized by digestion of total DNA with restriction enzymes. Epidemiol. Infect. 10:183-192.

13. Hesselbarth, J., W. Witte, C. Cuny, R. Rohde, and G. Amtsberg. 1994 Characterization of Staphylococcus intermedius from healthy dogs and cases of superficial pyoderma by DNA restriction endonuclease patterns. Vet. Microbiol. 41:259-266

14. Holt, J. G., N. R. Krieg, P. H. A. Sneath, J. T. Staley, and S. T. Williams 1994. Bergey's manual of determinative bacteriology, 9th ed., p. 527-557. The Williams \& Wilkins Co., Baltimore.

15. Ichiyama, S., M. Ohta, K. Shimokata, N. Kato, and J. Takeuchi. 1991 Genomic DNA fingerprinting by pulsed-field gel electrophoresis as an epidemiological marker for study of nosocomial infections caused by methicillin-resistant Staphylococcus aureus. J. Clin. Microbiol 29:2690-2695.

16. Igimi, S., E. Takahashi, and T. Mitsuoka. 1990. Staphylococcus schleifer subsp. coagulans subsp. nov., isolated from the external auditory meatus of dogs with external ear otitis. Int. J. Syst. Bacteriol. 40:409-411.

17. Iwahara, T., S. Ichiyama, T. Nada, K. Shimokata, and N. Nakashima. 1994 Clinical and epidemiologic investigations of nosocomial pulmonary infections caused by methicillin-resistant Staphylococcus aureus. Chest 105:826831
18. Jones, J. M., S. C. Yost, and P. A. Pattee. 1987. Transfer of the conjugal tetracycline resistance transposon Tn916 from Streptococcus faecalis to Staphylococcus aureus and identification of some insertion sites in the staphylococcal chromosome. J. Bacteriol. 169:2121-2131.

19. Khambaty, F. M., R. W. Bennett, and D. B. Shah. 1994. Application of pulsed-field gel electrophoresis to the epidemiological characterization of Staphylococcus intermedius implicated in a food-related outbreak. Epidemiol. Infect. 113:75-81.

20. Lina, B., M. Bes, F. Vandenesch, T. Greenland, J. Etienne, and J. Fleurette. 1993. Role of bacteriophages in genomic variability of related coagulasenegative staphylococci. FEMS Microbiol. Lett. 109:273-277.

21. Lina, B., F. Vandenesch, J. Etienne, B. Kreiswirth, and J. Fleurette. 1992. Comparison of coagulase-negative staphylococci by pulsed-field gel electrophoresis. FEMS Microbiol. Lett. 92:133-138.

22. Linhardt, F, W. Ziebuhr, P. Meyer, W. Witte, and J. Hacker, 1992. Pulsed field gel electrophoresis of genomic restriction fragments as a tool for the epidemiological analysis of Staphylococcus aureus and coagulase-negative staphylococci. FEMS Microbiol. Lett. 95:181-186.

23. Marples, R. R., and W. J. van Leeuwen. 1987. International Committee on Systematic Bacteriology Subcommittee on Phage Typing of Staphylococci Minutes of the meeting. Int. J. Syst. Bacteriol. 37:174-175

24. Nei, M., and W.-H. Li. 1979. Mathematical model for studying genetic variation in terms of restriction endonucleases. Proc. Natl. Acad. Sci. USA 76:5269-5273

25. Pattee, P. A. 1993. Genetic and physical map of Staphylococcus aureus NCTC 8325, p. 2.106-2.113. In S. J. O'Brien (ed.), Genetic maps, 6th ed. Cold Spring Harbor Laboratory Press, Cold Spring Harbor, N.Y.

26. Pattee, P. A., H.-C. Lee, and J. P. Bannantiene. 1990. Genetic and physical mapping of the chromosome of Staphylococcus aureus, p. 41-58. In R. P. Novick (ed.), Molecular biology of the staphylococci. VCH Publishers, New York.

27. Prevost, G., B. Jaulhac, and Y. Piemont. 1992. DNA fingerprinting by pulsed-field gel electrophoresis is more effective than ribotyping in distinguishing among methicillin-resistant Staphylococcus aureus isolates. J. Clin. Microbiol. 30:967-973.

28. Rosdahl, V. T., W. Witte, M. Musser, and J. O. Jarlov. 1994. Staphylococcus aureus strains of type 95. Spread of a single clone. Epidemiol. Infect. 113: $463-470$

29. Saulnier, P., C. Bourneix, G. Prevost, and A. Andremont. 1993. Random amplified polymorphic DNA assay is less discriminant than pulsed-field gel electrophoresis for typing strains of methicillin-resistant Staphylococcus aureus. J. Clin. Microbiol. 31:982-985.

30. Schlichting, C., C. Branger, J.-M. Fournier, W. Witte, A. Boutonnier, C. Wolz, P. Goullet, and G. Döring. 1993. Typing of Staphylococcus aureus by pulsed-field gel electrophoresis, zymotyping, capsular typing, and phage typing: resolution of clonal relationships. J. Clin. Microbiol. 31:227-232.

31. Schwarzkopf, A., H. Karch, H. Schmidt, W. Lenz, and J. Heesemann. 1993 Phenotypical and genotypical characterization of epidemic clumping factornegative, oxacillin-resistant Staphylococcus aureus. J. Clin. Microbiol. 31: 2281-2285.

32. Smeltzer, M. S., M. E. Hart, and J. J. Iandolo. 1994. The effect of lysogeny on the genomic organization of Staphylococcus aureus. Gene 138:51-57.

33. Snopková, Š., F. Götz, J. Doškař, and S. Rosypal. 1994. Pulsed field gel electrophoresis of the genomic restriction fragments of coagulase-negative staphylococci. FEMS Microbiol. Lett. 124:131-140.

34. Stewart, P. R., W. El-Adhami, B. Inglis, and J. C. Franklin. 1993. Analysis of an outbreak of variably methicillin-resistant Staphylococcus aureus with chromosomal RFLPs and mec region probes. J. Med. Microbiol. 38:270-277.

35. Struelens, M. J., R. Bax, A. Deplano, W. G. V. Quint, and A. van Belkum. 1993. Concordant clonal delineation of methicillin-resistant Staphylococcus aureus by macrorestriction analysis and polymerase chain reaction genome fingerprinting. J. Clin. Microbiol. 31:1964-1970.

36. Struelens, M. J., A. Deplano, C. Godard, N. Maes, and E. Serruys. 1992. Epidemiologic typing and delineation of genetic relatedness of methicillinresistant Staphylococcus aureus by macrorestriction analysis of genomic DNA using pulsed-field gel electrophoresis. J. Clin. Microbiol. 30:25992605

37. Upholt, W. B. 1977. Estimation of DNA sequence divergence from compar ison of restriction endonuclease digests. Nucleic Acids Res. 4:1257-1265.

38. Varaldo, P. E., R. Kilpper-Bälz, F. Biavaseo, G. Satta, and K. H. Schleifer. 1988. Staphylococcus delphini sp. nov., a coagulase-positive species isolated from dolphins. Int. J. Syst. Bacteriol. 38:436-439.

39. Wada, A., H. Ohta, K. Kulthanan, and K. Hiramatsu. 1993. Molecular cloning and mapping of 16S-23S rRNA gene complexes of Staphylococcus aureus. J. Bacteriol. 175:7483-7487.

40. Wanger, A. R., S. L. Morris, C. Ericson, K. V. Singh, and M. T. LaRocco. 1992. Latex agglutination-negative methicillin-resistant Staphylococcus aureus recovered from neonates: epidemiologic features and comparison of typing methods. J. Clin. Microbiol. 30:2583-2588. 